\title{
Does the Ecosystem Service Concept Reach its Limits in Urban Environments?
}

\section{Simone A. Beichler ${ }_{1,2}{ }^{*}$, Olaf Bastian, Dagmar Haase ${ }_{4,5}$, Stefan Heiland, Nadja Kabisch ${ }_{4,7}$, Felix Müllers}

1 Leibniz-Institute of Freshwater Ecology and Inland Fisheries (IGB), Department II Ecosystem Research, Müggelseedamm 310, D 12587 Berlin

2 HafenCity University Hamburg, Department of Urban Planning and Regional Development, Überseeallee 16, D 20457 Hamburg

3 City of Dresden, Environmental Office, P.O.Box 120020, D 01001 Dresden

4 Humboldt-University Berlin, Institute of Geography, Unter den Linden 6, D 10099 Berlin

5 Helmholtz Centre for Environmental Research - UFZ, Department of Computational Landscape Ecology, Permoserstr. 15, D 04318 Leipzig

6 Technische Universität Berlin, Chair of Landscape Planning and Development, Sekr. EB 5, Str. des 17. Juni 145, D

10623 Berlin

7 Helmholtz Centre for Environmental Research - UFZ, Department of Urban and Environmental Sociology, Permoserstr. 15, D 04318 Leipzig

8 University of Kiel, Institute for Natural Resource Conservation, Olshausenstrasse 75, D 24118 Kiel

\begin{abstract}
There is a rapidly growing body of literature on the theory about the ecosystem service concept and the practical assessment of ecosystem services in different contexts ranging from natural to urban environments. Yet, where does the concept reach its limits? This paper critically reflects the application of the ecosystem service concept in urban environments illustrating the handling of urban structures (incl. built-up areas) and the risk that the normative principle of the concept could be missed. It is shown that in theory urban structures refer to a variety of ecosystem concepts. As a starting point for ecosystem service assessments, these could be classified into natural, managed, constructed and overbuilt systems. Since ecosystem service concepts do not directly refer to a specific ecosystem definition, but to biophysical structures and processes, all of these classes could be included. However, the dependency on context and scale makes a differentiation in practical ecosystem services assessment challenging. We conclude that the ecosystem service concept does not reach its limits in urban environments, but urban environments represent an extreme case characterized by multifunctionality and a high degree of modification that enables to uncover research challenges applying in any environment. There is a need for a more transparent reporting of theoretical and methodological assumptions to facilitate the comparability between ecosystem service assessments. Comprehensive approaches that consider multiple ecosystem services and include human input, human modification, the ecosystem status as well as their interactions are required to understand the spatial relations between ecosystem services delivered by different ecosystems.
\end{abstract}

\section{Keywords:}

ecosystem definition, urban ecosystem services, normative principle, human input, trade-off, land use, ecosystem service bundles

Submitted: 21 May 2016 / Accepted in revised form: 04 May 2017 / Published: 04 June 2017

*Corresponding author. Email: beichler@igb-berlin.de

(C) The Authors. 2017. Landscape Online. This is an Open Access article distributed under the terms of the Creative Commons Attribution License (http://creativecommons.org/licenses/by/4.0), which permits unrestricted use, distribution, and reproduction in any medium, provided the original work is properly cited. 


\section{Introduction}

A fter the milestone publications of Ehrlich and Ehrlich (1981), Daily (1997), Costanza (1997) and the Millennium Ecosystem Assessment (2005), the concept of ecosystem services has been widely recognized by scientists of various disciplines. It has developed into a productive framework resulting in a rapidly growing number of case studies (MartínezHarms \& Balvanera, 2012) dealing with the valuation of benefits derived from ecosystems. Initially, most of these studies were concerned with natural or seminatural areas such as forests, wetlands, peat bogs and natural grasslands, wherein results could serve as an (additional) argument for nature conservation. Recently, the number of studies performed in urban environments dealing with urban ecosystem services has increased (Haase et al., 2014). Yet, the basic idea of the ecosystem service concept, is to give a value to the benefits derived from ecosystems, referring to the internalisation of the intangible values of nature into decision making; in a way that "[...] everyday decision and behaviour will be channelled toward a future in which nature is no longer seen as luxury we cannot afford, but as something essential for sustaining and improving human well-being" (Daily et al., 2009, p. 27). This gives way to the question of whether in this context all kinds of urban structures (including built-up land) can be regarded as nature or ecosystems and thus the ecosystem services approach applies. Interestingly, while this question is frequently raised in the context of conference discussions it is hardly ever addressed in publications. Thus, the objective of this paper is to illustrate the ongoing scientific discussion on the overall question 'Does the Ecosystem Service Concept Reach its Limits in Urban Environments' by compiling arguments from literature and conversations with colleagues from different disciplines.

The discrepancy between conference discussions and publications in dealing with this issue is rooted in two different suppositions in the field of urban ecosystem service research. Firstly, there is a general acceptance that the definition of the ecosystem concept is contested and very flexible. As defined by Odum et al. (1971, p. 8) an ecosystem is "any unit that includes all of the organisms in a given area interacting with the physical environment so that a flow of energy leads to a clearly defined trophic structure, abiotic diversity and material cycling". Thus the concept might be applied in "any case where organisms and physical processes interact in some spatial arena"(Pickett \& Cadenasso, 2002, p. 2). Therewith, an application of this ecosystem concept in any urban structure including built-up land is scientifically valid. Nevertheless, apart from the core definition, the ecosystem concept needs to be specified with regard to the case study, resulting in a variety of models (Pickett \& Cadenasso, 2002). Secondly, the ecosystem service concept is often criticized as it could promote an exploitative humannature relationship and due to the danger that the intrinsic value of nature in its own right is depreciated or ignored (Schröter et al., 2014). These issues are of high relevance in urban environments considering the human impact and effects of urbanisation. In this context regarding all urban structures as ecosystems seems problematic, because it could imply that there is no need for nature conservation as the "destruction of nature" leads to a new kind of ecosystem. Conversely, most papers on ecosystem services in cities emphasize urban nature's value with its benefits for humans. It can be argued, that the critique is countervailed by the underlying aim, namely to give environmental interests a higher status in decision-making. Showing the functionality of ecosystems could facilitate nature conservation and does explicitly not exclude the intrinsic value of 'nature' (Schröter et al., 2014). However, an inclusion of all kinds of urban structures could imply that humans are able not only to enhance ecosystem services but also to create them artificially. For instance, in-situ rainwater infillment areas are based on a completely artificial but extremely effective substrate. Such an application contradicts the meaning of the ecosystem service concept, because here e.g. the regulation of water of an intact (natural) river system is valued, especially because technical measures (e.g. dam) are dispensable. Consequently, a general inclusion of all urban structures into the ecosystem service concept involves the risk that the normative principle of the ecosystem service concept is missed. Nevertheless, there are examples showing that urban structures contribute to the 
provision of ecosystem services (Haase et al., 2014; Milcu et al., 2013).

Resulting from human activities, urban areas combine the dominating built-up structures with open spaces. The latter are referred to as urban blue and green areas, that are in the focus of most ecosystem service assessment studies performed in urban environments (Haase et al., 2014). Thus we can safely argue that urban green and blue spaces provide a lot of different ecosystem services in the urban context (Bezák \& Lyytimäki, 2011). In terms of land use classes, built-up space mostly refers to housing, industry and transport (Larondelle et al., 2014a). These land use patterns include sealed surfaces (e.g. streets) and built-up ones (e.g. houses) alongside various different types of ecosystems such as private gardens, street trees, and pastures. Against this background, it appears reasonable to scrutinize whether or not the ecosystem service concept can be applied if only man-made ecosystem components are involved. However, human activities have profound impacts on ecosystems worldwide (Mooney et al., 2009). In this context, it represents a challenge to distinguish natural from semi-natural and cultivated man-made systems (de Groot et al., 2010) and to decide whether they could be regarded as ecosystems - or if their services could be defined as ecosystem services. However, if urban structures and the human dimension are ignored or oversimplified, studies devised to reduce ecological impacts could fail to identify underlying mechanisms (Alberti, 2005).

This paper aims at providing an overview on ecosystem service approaches in urban environments and discussing the handling of urban structures as subjects capable of providing ecosystem services or not. This problem is directly connected to the link between the ecosystem definition and the ecosystem service concept, which often remains vague, but is a key issue in the urban context. Against this background, we firstly address the challenge to draw a definite borderline to distinguish ecological and non ecological urban structures referring to the question 1) Which urban structures can be differentiated as a starting point for ecosystem service assessments? We discuss the ecosystem concept in the urban context and propose a more distinct classification of types of urban ecological structures. These classes serve as a basis to reflect upon the theoretical applicability of different ecosystem service concepts to answer the question: 2) Which services provided by urban structures can be understood as ecosystem services? We particularly discuss whether different urban structures should be included in existing ecosystem service frameworks or if adaptations and extensions are needed. Thirdly, different ecosystem service assessment approaches are reflected referring to the question 3) Are the theoretical considerations and differentiations viable in ecosystem service assessment? Finally, we discuss implications for the applications of the ecosystem service approach in urban environments and reflect upon the key question whether the ecosystem service concept reaches its limits in urban environments.

This communication and opinion paper is based on broad literature knowledge and own expert knowledge. Throughout the discussion process in the development of this paper, key issues have been identified, which are summarized for each section. These key issues relate on the one hand to decisive theoretical points of the section. On the other hand, they relate to pending research questions or issues with controversial viewpoints.

\section{Urban areas - built-up ecosystems?}

$T$ he theoretical foundation for ecosystem services in urban areas is less specific than for e.g. forest landscapes. There is no standardized definition for urban areas (Gómez-Baggethun \& Barton, 2013; Haase, 2014) and the borders between urban, semiurban, agricultural and natural areas remain fuzzy (Bezák \& Lyytimäki, 2011). Thus in practice a city's boundary, either refers to administrative units or is defined based on e.g. population density or to the amount or share of the built-up areas. However, most ecological processes exceed those boundaries, thus it is feasible to consider areas from the urban core to the hinterland as urban region (Gómez-Baggethun $\&$ Barton, 2013). In this regard, the functioning of ecosystems in a city refers to the "ecology in cities", 
whereas the interconnections to the surrounding landscape refer to the "ecology of cities"(Jansson, 2013). The significant impacts of urbanisation result in complex interactions between economic, social and ecological processes (Alberti, 2005).

\subsection{The ecosystem concept}

The term and concept of the ecosystem originated with Tansley (1935). An ecosystem in its common usage is considered a biotic community plus its abiotic environment and their interrelationships. It is considered an entity that subsumes a discrete community. Applied in cities this includes humans (biotic) and their built-up structures (abiotic) alongside flora, fauna and their abiotic environment. As Bolund \& Hunhammar (1999) put it: „When humanity is considered a part of nature, cities themselves can be regarded as a global network of ecosystems". Moreover, they stated that a city could be defined as either one ecosystem or an assembly of ecosystems. The latter allows reflecting the individual entities in a city. Kowarik (1992) differentiates between four types of nature in cities:

1) remains of the original natural landscape

2) cultural landscapes

3) horticultural designed green spaces and

4) specific urban / industrial nature.

In line with the previous arguments, the first and probably the second type fit into the definition of an ecosystem in a strict sense with regard to the biotic and abiotic aspects. The third and the fourth type of nature acknowledge that the biotic as well as the abiotic conditions have been significantly altered by humans. These can be referred to as novel ecosystems (Kowarik, 2011). Novel ecosystems as defined by Hobbs et al. (2006, p. 2) are characterized by novelty and human agency and "result from biotic responses to human induced abiotic conditions and/ or novel biotic elements". All types of ecosystems in urban regions could be regarded as novel ecosystems as the biotic and abiotic conditions have been altered and also near natural ecosystems are heavily influenced by the urban surroundings. Yet, agricultural systems are heavily manipulated as well, thus could be regarded novel ecosystems.

The Total Human Ecosystem is defined as the complex sum of all landscapes, interacting and integrating with human beings (Naveh \& Lieberman, 1994; Naveh, 2000). This approach is suggested as a guiding conceptual principle for a transdisciplinary and systems-based approach to landscape ecology. In summary, a city is a total human ecosystem, while some parts of a city can still be regarded as ecosystems in a strict sense, some are novel ecosystems and some are not at all ecosystems in the classical sense. Through time there has been a conceptual shift in science focussing on processes instead of structural entities (Currie, 2011). "A process-oriented approach frames ecosystem processes as one integrated subset of processes operating across scales, but not necessarily all of the processes that operate within a boundary, to create an entity called the ecosystem" (Currie, 2011).

\subsection{Urban structures}

In urban regions, the level of ecosystem transformation covers the whole range from original natural to novel urban ecosystems (Kowarik, 2011). Ecosystems converted to another type of land cover can be characterized by management or land use types (de Groot et al., 2010). The different types of urban structures we have to deal with are shown in Table 1. Urban land use is characterized by a high degree of and huge variation in imperviousness (Breuste et al., 2013a; Haase, 2014), thus the degree of ecosystem transformation is indicated by the mean percentage of sealed surface and built-up area (Table 1). Sealed surface can be defined as the sum of paved surfaces, asphalt and built-up, while built-up area consists of all forms of houses such as detached, terraced or multi-story houses, but also include industrial or factory buildings or buildings for mixed use (Pauleit \& Duhme, 2000). The vegetation cover indicates the degree of naturalness, which can be related to the four types of urban nature.

Studies on ecosystem services frequently focus on urban blue and green areas (Table 1). Those in principle include all terrestrial and aquatic ecosystems within the urban areas ranging from 
urban forests to sports fields and from lakes to ponds (Kabisch \& Haase, 2013). Remains of original nature ( $1^{\text {st }}$ type of nature) are scarce to non-existent in cities, but might be found in woodlands, urban forests, lakes, ponds and streams as such here the strict ecosystem definition could be applied. The other types of urban blue and green areas could be referred to as ecosystem as well, due to the high share of vegetation or water body habitats. Yet, the degree of human influence is high in terms of management and pollutions, thus the concept of novel ecosystems applies, but a differentiation into the types of nature is difficult. The group of urban agriculture includes arable fields ( $2^{\text {nd }}$ type of urban nature) and horticulture ( $3^{\text {rd }}$ type of urban nature), that can be regarded as ecosystems. However, the biotic and abiotic components are continuously heavily managed and human input is very high (Knapp, 2014). That raises the question what role the aspect of human impact plays when evaluating whether the ecosystem concept still applies. In order to consistently integrate this constellation within a conceptual framework, one can argue that urban structures could be handled alike all managed ecosystems.

Table 1: Overview of the urban structures including built-up spaces and open spaces. \% refer to the mean percentage shares of unit area. Adapted after Haase \& Nuissl (2010), Urban Atlas data base (Larondelle et al., 2014a) and Pauleit \& Duhme (2000).

\begin{tabular}{|c|c|c|c|c|c|}
\hline \multicolumn{3}{|c|}{ Urban structures } & \multirow{2}{*}{$\begin{array}{c}\begin{array}{c}\text { Sealed } \\
\text { surface (\%) }\end{array} \\
30.5 \\
\end{array}$} & \multirow{2}{*}{$\begin{array}{c}\text { Built-up (\%) } \\
15.3 \\
\end{array}$} & \multirow{2}{*}{$\begin{array}{c}\begin{array}{c}\text { Vegetated } \\
(\%)\end{array} \\
66.8 \\
\end{array}$} \\
\hline \multirow{14}{*}{ 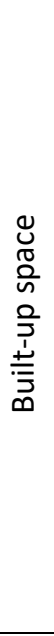 } & \multirow[t]{4}{*}{ Housing } & Detached houses & & & \\
\hline & & Terraced houses & 46.4 & 29.0 & 52.5 \\
\hline & & Multistory houses & 51.5 & 29.5 & 43.8 \\
\hline & & Multistory blocks & 79.9 & 44.3 & 19.1 \\
\hline & \multirow[t]{6}{*}{ Industry } & Factory buildings & 46.3 & 23.9 & 31.8 \\
\hline & & Multistory/factory buildings & 75.7 & 35.2 & 12.8 \\
\hline & & Mixed use & 36.7 & 22.0 & 59.1 \\
\hline & & Special buildings & 50.0 & 22.5 & 41.3 \\
\hline & & Construction sites & 8.0 & 3.9 & 16.0 \\
\hline & & Large car parks & 59.3 & 5.8 & 15.9 \\
\hline & \multirow[t]{4}{*}{ Transport } & Roads & 90.8 & 0.2 & 6.9 \\
\hline & & Railways & 7.4 & 1.2 & 8.1 \\
\hline & & Airports & 85 & & \\
\hline & & Port areas & 85 & & \\
\hline \multirow{13}{*}{ 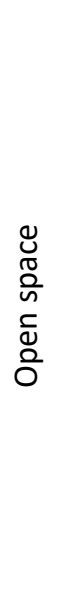 } & \multirow{2}{*}{$\begin{array}{l}\text { Urban } \\
\text { Blue }\end{array}$} & Lakes and ponds & 0.0 & 0.0 & 0.0 \\
\hline & & Streams & 9.3 & 0.3 & 52.8 \\
\hline & \multirow{8}{*}{$\begin{array}{l}\text { Urban } \\
\text { green }\end{array}$} & Woodlands & 0.5 & 0.0 & 96.7 \\
\hline & & Hedgerows/woodlots & 13.3 & 0.7 & 83.4 \\
\hline & & Parks and green spaces & 12.7 & 0.9 & 77.6 \\
\hline & & Cemeteries & 2.3 & 1.3 & 88.0 \\
\hline & & Allotment gardens & 16.1 & 11.0 & 77.2 \\
\hline & & Sports fields & 14.1 & 3.7 & 73.6 \\
\hline & & Meadows and pastures & 7.7 & 4.1 & 88.1 \\
\hline & & Extensive grasslands & 1.8 & 0.3 & 80.1 \\
\hline & & $\begin{array}{l}\text { Land without current } \\
\text { use(brownfield) }\end{array}$ & 10.12 & & \\
\hline & \multirow{2}{*}{$\begin{array}{l}\text { Urban } \\
\text { agriculture }\end{array}$} & Arable fields & 1.2 & 0.2 & 96.7 \\
\hline & & Horticulture/nurseries & 25.1 & 19.9 & 68.8 \\
\hline
\end{tabular}


Considering the group of built-up spaces an ambiguous picture can be recognized, e.g. terraced houses with ca. $50 \%$ of sealed and vegetated area plus $29 \%$ of built-up area (Table 1 ). That is attributable in particular to the following two points. First, the urban land use classes represent a pattern, not a single patch. Whether we look at a single (potentially natural) patch or a mosaic of built-up structures and natural components is essentially a problem of scale. With regard to urban planning one can differentiate e.g. four different scales: building, street, neighbourhood, region (GómezBaggethun \& Barton, 2013). Secondly, these scale problems exacerbate in urban environments that exhibit another "vertical" dimension of scale. That means one patch could include built-up structures (e.g. a house) and ecological structures (e.g. green roof) at the same time. Therefore, urban land use has a unique multifunctionality (Haase, 2014). In the evaluation of the practical applicability of the ecosystem concept those scalar issues have to be considered. Urban green includes also yards and gardens that can be attributed to the categories of housing (Table 1). Industry and transport (Table 1) could contain green areas by means of street trees and lawns in front of buildings. Those small and scattered areas belong to what is described as urban green infrastructure. This includes not only urban blue and green, but also private gardens, roadsides and rail yards meaning all areas neither covered nor sealed. In addition single trees, green walls, and green roofs can be regarded as part of the green infrastructure (Wang et al., 2014). In the planning context green infrastructure is designed and managed to deliver a wide range of ecosystem services (EC, 2013) addressing the (sub-regional) network of green spaces (Bezák \& Lyytimäki, 2011). However, it is questionable whether in this context the overall network represents an ecosystem with its interacting biotic community or whether the single components (e.g. a street tree) already represent an ecosystem. This question feeds back to the problem of scale pointing at the fact that the ecosystem is a theoretical construct, for which the definition depends on the particular problem under consideration.

\subsection{Types of urban ecosystems}

Taking a process-oriented approach in defining urban ecosystem (cf. section 2.1) allows for the inclusion of urban built-up structures while focussing on ecological processes that contribute to human well-being. However, considering the initial aim of the ecosystem service concept (cf. section 2) to prevent natural and semi-natural ecosystems from impairment by pollution, erosion, disturbance of species or land consumption by built-up areas, the process definition could be too broad. Urban regions are strongly shaped by humans wherein natural, cultural, and built-up areas are closely intertwined. In the resulting complex human-environmental system, we have to deal with very different types of (potential) ecosystems that relate to different ecosystem definitions.

Humans are an interactive component of the system enhancing and destroying the basis for ecosystem services, by disrupting ecosystem processes through e.g. ploughing, water extraction and city building (Mooney et al., 2009). Thus, although urban environments are an extreme case, most of the ecosystems on earth are modified or even artificially created and maintained by humans. It represents a challenge to draw a definite borderline. We propose a more distinct classification of types of urban structures (Figure 1) considering the degree of naturalness (regarding original ecosystem components), the ecosystem definition and humaninduced changes (biotic or abiotic, process or structure). Hemeroby as described by Sukopp (1969) is an index that measures the human influence on ecosystems considering the intensity, frequency and the spatial extent of the disturbance. Accordingly, in order to take account of the specific characteristics of urban environments, we differentiate between human modification and input. Modification refers to human activities that alter (long-term) biophysical structures by soil sealing, selection of species etc., which provoke a development from natural to constructed ecosystems as illustrated in Figure 1. Human input refers to human activities that are aimed at influencing (short-term, continuously) mainly biophysical processes by cutting, fertilizer input etc., which is highest for managed and 
constructed ecosystems (Figure 1). The transition between both classes of human activities can be fluent, for example, the high human input with regard to agricultural practices on the long term essentially modifies the biophysical structures. The human input mostly refers directly to the optimization of a particular ecosystem service. The human modification mostly refers to spatial development (e.g. soil sealing related to settlements) impairing ecosystems and related services. However, depending on architectural style and construction material some ecosystem components may remain.

- Natural or near-natural ecosystems, that relate to the ecosystem definition in a strict sense, though these areas might have been altered during early urbanisation, the human influence is low. Examples may be some lakes, rivers, forests, wet areas.

- Managed ecosystems are still based on original ecosystem components, but these areas are continuously influenced and managed by humans. This class includes for example arable fields, historical cultural landscape elements (e.g. heaths, cemeteries), parks, but also parts of the green infrastructure like gardens and roadsides.

- Overbuilt (eco)systems refer to all built-up or sealed areas where the human modification is very high, but some ecosystem components are retained. These relate to the broad concept of the novel ecosystems and the ecosystem definition focussing on processes, as the rudimentary ecological structures are hardly quantifiable. Examples are parking lots with grass pavers, and other areas where ecological processes are taking place.

- Constructed (eco)systems relate to systems without original ecosystem components, but with man-made ecosystem structures that form new/ artificial habitats and the associated biocenosis. These systems may be regarded as parts of the Total Human Ecosystem (Naveh, 2000). However, they could also be regarded an ecosystem in terms of a process related definition as ecological processes are taking place. Examples are green roofs, vertical gardening, green bridges and canals.
In Figure 1, the proposed classes are assigned to main groups of urban structures (cf. Table 1). To exemplify, "natural or near-natural ecosystems" are characterized by a low degree modification, low input and high share of original natural components, which can mainly be found in urban blue and green areas and to less extent in urban structures labelled urban agriculture. Although, the proposed types of urban ecosystems are not mutually exclusive, as the distinctions are fuzzy, the classification attempts to clarify the differences between the structures that need to be dealt with in urban environments. It remains an open debate, whether all classes could be considered ecosystems. The main issues we encountered during discussion are summarized in the box below. Nonetheless, the proposed classification allows for a more structured approach to discussing whether the ecosystem service concept can be applied.

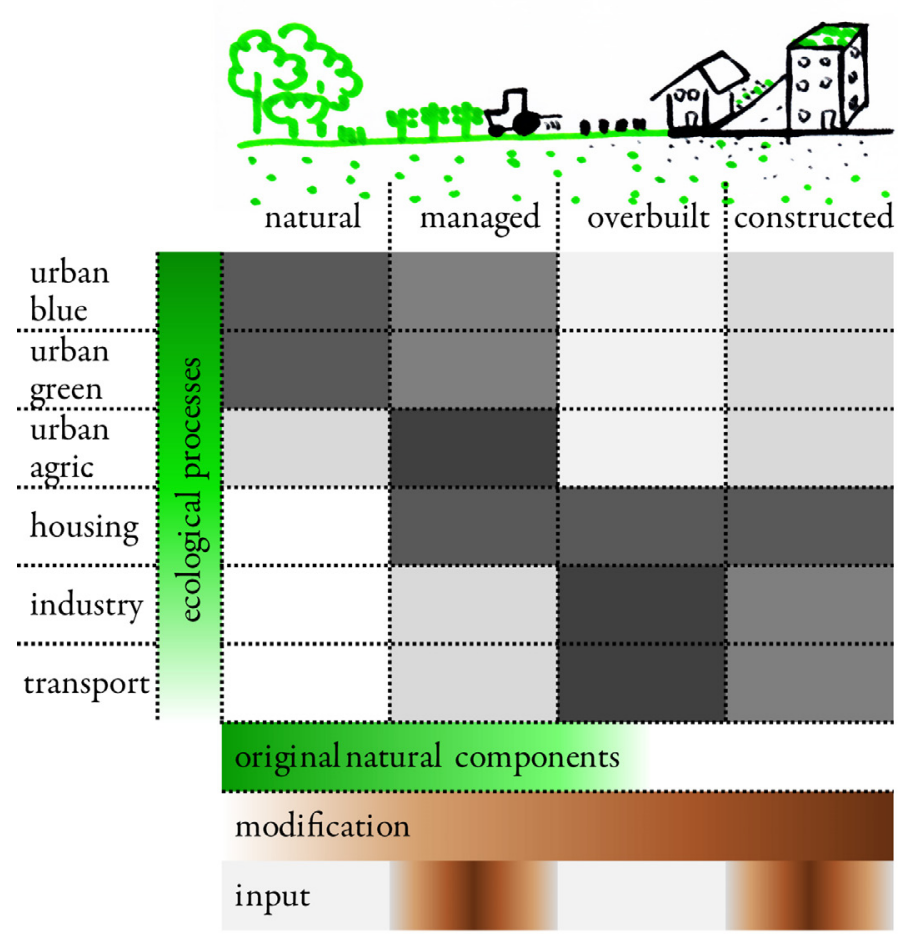

Figure 1: Types of urban ecosystems. The darker the grey the higher the potential proportion of the urban ecosystem type within the individual urban structure classes. Accordingly, the green colour gradient indicates the natural components remaining and the ecological processes taking place. The brown colour scheme illustrates human input and modification the darker the colour the higher is the human influence. 


\section{Key Issues}

- Humans are at the same time part of the system and the main actors that change the system properties that are relevant for the definition of ecosystems.

- The transition between human input and modification is fuzzy.

\section{Conceptual considerations}

I In the Millennium Ecosystem Assessment (MEA, 2005, p. V) ecosystem services are described as "the benefits people obtain from ecosystems". The development of detailed terminology, concepts and frameworks on ecosystem service classification, functions, values, and benefits are still part of a lively scientific discourse (de Groot et al., 2010; Hermann et al., 2011). There are different classification schemes for ecosystem services (Hermann et al., 2011). In general, provisioning/ production services, regulating services and cultural services are distinguished (Burkhard et al., 2014; MEA, 2005). It has been shown that examples for all of them are found in urban environments, but often case studies focus solely on one category (Haase et al., 2014). Lamarque et al. (2011) compare various concepts including ecological services, ecosystem services, landscape services, land functions and environmental functions. They conclude that the approaches differ in the intensity of ecological knowledge required, in the objective and the relevance at different scales. It needs to be acknowledged that the different concepts are not mutually exclusive, but points of discussions are related to particular definitions and distinctions between the elements of the framework. As such, in order to capture the multiple dimensions and specific aspects of the ecosystem service concept, it is currently common ground that a detailed approach tailored to the purpose of a study is needed (Hermann et al., 2011). In this section, we elaborate whether the different urban structures natural, managed, overbuilt and constructed could or should be included under known frameworks or where adaptations and extensions are necessary.

\subsection{Applicability of ecosystem service frameworks in urban areas}

Treating urban systems as ecosystems is consistent with the Millennium Ecosystem Assessment, where in relatively undisturbed as well as intensively managed and modified areas are included in the ecosystem service concept (MEA, 2005). However, it also states that not all urban systems are necessarily ecosystems and specify that "ecosystems are understood to be biophysical systems, and the value of ecosystem services is assumed to be distinct from the value intentionally added through the application of human labor" (MEA, 2005, p. 799). Thus, although the MEA mentions that not only natural ecosystems should be included, it remains unclear whether or not to include overbuilt and constructed (eco) systems, because "human labor" is not specified.

The different aspects of the ecosystem service concept were presented by Haines-Young and Potschin (2010) as a cascade starting with structures and processes that exhibit functions, which turn into services if used, ending up with the benefits people derive. In contrast, the Ecosystem Properties Potentials Service (EPPS) framework includes a special focus on ecosystem potentials to provide ecosystem services independently of their use (Bastian et al., 2012, 2013). Herein the ecosystem properties are described by structures and processes. The first block of the ecosystem service cascade does not directly refer to ecosystems, but to "ecological structures and processes created or generated by living organisms" (Haines-Young \& Potschin, 2010, p. 115). Müller et al. (2010b) refer to this first block as "biophysical structures and processes". Thus, the concepts refer to both, the broad process and entity related ecosystem definitions (cf. section 3 ). By definition in all four types of urban structures (cf. section 2.3), ecological processes are taking place that contribute to one or more ecosystem services. Yet, whether the structures within all four types of urban structures can be regarded as being ecological is questionable. In this context the different ecosystem service frameworks remain unclear on 
the question whether it would be sufficient if either structures or processes were ecological, as a basis for the provision of ecosystem services. Urban builtup structures could be regarded as being physical structures that exhibit special properties for living organisms that generate ecological processes. There is a need to clarify, which level of human modification (Figure 1) marks the borderline to distinguish urban structures which - in a concrete case - could be regarded as ecosystems from those which cannot, and additionally to distinguish those which can provide ecosystem services from those which cannot. However, this point of discussion corresponds to the line of argument concerning the ecosystem definition (section 2 ).

A refinement of the ecosystem service definition by Burkhard et al. (2012a) underlines the integration of a human management component by integrating contributions of ecosystems "in combination with other inputs" into the definition. As described in section 2.3 ecological structures and processes are influenced by human input and modification. Accordingly, at the starting point all urban structures (or any system), could be the object/area of study in ecosystem service assessments, as the examination of structures and processes as well as input and modification would allow for distinguishing between ecosystem services and man-made services. However, modifications and input are interacting as well as structures and processes. It still represents a scientific challenge to take systematic account of the effects of human influences on ecosystems, ecosystem services and related values (Burkhard et al., 2014; Daily et al., 2009; de Groot et al., 2010). For example, the intensive management practices influencing structures and processes in agricultural systems make it very difficult to distinguish the human input and the service actually provided by the (managed) ecosystem (Burkhard et al., 2014).

The potential approach in the EPPS framework (Bastian et al., 2012) emphasizes the importance of biophysical prerequisites and conditions of ecosystems. Although, the EPPS framework in principle refers to ecosystems, it bears the opportunity also to deal with all urban structures. To exemplify, in a parking lot ecological structures are modified to a high degree, but with grass pavers some ecosystem structures (e.g. grass, soil) and processes (e.g. water cycle) could be maintained. Taking the EPPS approach would allow to focus on the potential for ecosystem services in overbuilt (eco)systems and therewith indicating options for land use management favouring ecosystem services. However, what would it mean if in a parking lot artificial substrates were introduced to stabilise the pavers, which allows grass to grow on top? Could the water flow regulation be still an ecosystem service, whereas the services provided by the grass are manmade? In principle, ecosystems might be man-made (constructed ecosystems), but services provided by an artificial substrate are not defined as ecosystem service. There is a gradual transition between natural and human influences related to an increasing share of artificial or technical material. In this connection, the question how to deal with an artificial element that promotes ecological processes is not explicitly addressed in the concepts.

An area that is not considered an ecosystem cannot contribute to the supply of ecosystem service. However, considering entire landscapes the term landscape services could be applied, as it refers not only to ecosystem features, but also to landscape elements. Vallés-Planells et al. (2014) proposed the application of the concept of landscape services in a broader sense integrating contributions to human well-being by ecosystems and human process including other man-made services like "living space". Yet, carried to extreme it would mean to value nature just for the area it provides, which would be contrary to the normative principle of the ecosystem service concept. We argue that landscape services are a specification of the ecosystem service concept, where in the landscape character, landscape elements and spatial interaction between patches are of relevance (Bastian et al., 2014; Termorshuizen \& Opdam, 2009). The term landscape services is not exclusive and might also be applied for ecosystems wherever it is meaningful e.g. considering complex entire landscapes.

\subsection{Normative principles of the ecosystem service concept}

From a scientific point of view the concepts discussed so far, allow for an inclusion of all urban structures in 
the assessment of ecosystem services. This brings us back to the question whether considering services provided by highly modified systems as ecosystem services is still consistent with the normative principles of the ecosystem service concept (referring to contributions of 'nature' as described in the introduction). It might be misleading if the value of natural ecosystems could be equal to constructed (eco)systems. In this context Hobbs et al. (2006) state that the relative value of novel ecosystems should be seen in relation to the ecosystem services lost from the other ecosystem type. To characterize ecosystem performance not only ecosystem services, but also the ecosystem state should be considered (Müller et al., 2010b). In this regard, ecosystem structures and processes determine the state of the system, which depends on ecological integrity (Müller \& Burkhard, 2012). The concept of integrity refers to the selforganizing capacity of the system (Müller \& Burkhard, 2012) and includes several structural and functional variables to determine the status of the ecosystem (Burkhard et al., 2012b; Kandziora et al., 2013; Müller et al., 2010a). Thus, special attention needs to be devoted to the issue of long-term ecosystem integrity, as it could be used to differentiate between services provided by ecosystems and other manmade systems (Currie, 2011).

The ecosystem service concept considers not only ecological structures and processes, but also human benefits and values, and thus is a tool to analyse social-ecological systems (Müller et al., 2010b; Spangenberg et al., 2014). Both the ecosystem service supply and demand are considered (Burkhard et al., 2012b, 2010a). The supply refers to the capacity of an area to provide ecosystem services and the demand refers to the sum of all ecosystem services currently and potentially being used in a particular area (Burkhard et al., 2012b). The relation between supply and demand is of special interest when discussing the importance of the different urban structures in providing ecosystem services. In cities, on the one hand, there is a strong spatial proximity of supply and demand. On the other hand, the demand side is very prominent, as there is a scarcity of ecosystems faced with a high density of beneficiaries (Gómez-Baggethun \& Barton, 2013). Hence, in urban environments the ecosystem service supply capacity decreases, while the relative importance (for well-being) increases. Thus, with regard to the supply-demand relation, a constructed ecosystem is certainly of low relevance in rural areas, but of very high relevance in urban areas. That is also true for the ecological importance for example in terms of ecological connectivity or the provision of habitat. Consequently, an inclusion of all urban structures as ones providing ecosystem services is not only consistent with the normative principles of the ecosystem service concept, but of high interest due to the deficit in supply in urban environments.

Key Issues
- Is it feasible and useful to consider structures
and processes separately in the definition of
ecosystem services?
- Urban ecosystem services result from a
mixture of anthropogenic activities and
natural processes. There are gradients
regarding human input, human modification
and ecological factors. What if artificial
elements support ecological processes?

\section{Assessment methods}

So far, the discussion focussed on theoretical $S$ considerations regarding the basic ecosystem concept and the different ecosystem service frameworks. These preliminary considerations of any study in an urban environment are a basic part of scientific research, but a common shortcoming is the adequate and transparent reporting of approaches and associated methods (MartínezHarms \& Balvanera, 2012; Seppelt et al., 2012). In accordance, it is often not possible to trace back arguments and information that led to the decision on including or excluding urban built-up structures within a proposed assessment approach. There are various different approaches to assess ecosystem services, that can roughly be differentiated into monetary, non-monetary, ecological and socio- 
cultural approaches (Haase et al., 2014; Hermann et al., 2011). This chapter attempts to discuss methodological considerations with regard to the inclusion of urban structures.

\subsection{Restriction of the study area}

Frequently urban ecosystem service assessments start with a focus on green and blue areas, thus primarily refer to natural and managed ecosystems. As discussed based on the strict ecosystem definition, it is feasible to argue that urban builtup structures (including overbuilt and constructed (eco)systems) are no (relevant) ecosystems, thus should not be valued at all. This refers to the scale of the study in terms of the geographical spatial boundary of the study area and the categorical decision (e.g. the whole city or specific blue and green areas within this city). Consequently, ecosystem service maps contain multiple blind spots. That does not mean that these areas include no ecosystems, it rather simply refers to areas that have not been assessed. Here, various examples can be found assessing special types, such as managed ecosystems, e.g. urban parks (Breuste et al., 2013b; Voigt et al., 2014), but there are also examples regarding constructed ecosystems, e.g. green roofs (Oberndorfer et al., 2007). These approaches apply an entity based ecosystem definition, but circumvent the problem of differentiating between the different types of ecosystems. That in turn bears the risk that the respective values of the single studies might be compared against one another, without consideration of differences in terms of ecosystem integrity, human input or modification.

\subsection{Data constraints and the problem of scale}

Land use and land cover based assessments are frequent (Martínez-Harms \& Balvanera, 2012). In this context, in the beginning the overall city border or the functional urban region (Larondelle et al., 2014a) sets the boundary of the case study area in most cases. Often ecosystem service assessments are based on pre-classified land use / land cover data such as CORINE land cover, Urban Atlas database or ATKIS data (German Official Topographic-Cartographic
Information System) ranging from broad to fine resolution (Burkhard et al., 2010a; Kabisch \& Haase, 2014). Here, methodological difficulties often arise from the mixture of information on land use and land cover within one dataset (Breuste et al., 2013a). The bigger the area under consideration and the lower the resolution, the higher is the probability that present ecosystems might be missed or built-up structures might be included in ecosystem service assessments pointing at the problem of scale. To exemplify, treating settlements not as ecosystem excludes smaller ecological structures (e.g. private gardens) from analyses and treating parks as ecosystem includes non ecological infrastructure elements (e.g. roads, houses) in the analysis, respectively. Though, the challenge of scaling issues and the need for multi-scale approaches is often indicated in literature (Alberti, 2005; Burkhard et al., 2010b; de Groot et al., 2010), a detailed description of associated methodological considerations is rare. Researchers are facing considerable challenges in terms of data availability and statistical methods (aggregation, disaggregation) (Scholes et al., 2013). One could argue that urban structures like single trees, green roofs and lawns are beyond the scale of consideration. However, most ecosystem service assessment approaches use combinatory matrices of indicators or even models that are aggregated at the resulting scale. These indicators could be leaf area (sqm) or the abundance of species (e.g. birds, butterflies) (Gómez-Baggethun \& Barton, 2013), which are measured at the same spatial scale as those ecosystems. Thus, the scale of measurement gives no ground for excluding constructed, overbuilt or very small and scattered ecosystems. The use of satellite images starts with the identification of urban green structures taking for example the proportion of sealed surface as an indicator to differentiate between urban built-up structures and "ecological" structures. However, thinking of green roofs points out potential methodological pitfalls in this context, as constructed ecosystems might be included while overbuilt ecosystems are excluded.

The approaches so far could be summarized as starting with land use/land cover to characterize the type of ecosystem. In addition, there are studies starting with the ecosystem service, which 
is related to different research questions, but could be combined with the aforementioned approaches. That is frequently done in the context of climate change research, such as studies aimed at the identification of areas that contribute to the local climate regulation (Larondelle et al., 2014a; Schwarz et al., 2011). Here, a process related definition of ecosystems applies, which might include the whole range from natural to constructed ecosystems. Nevertheless, in general due to data constraints it is often technically not possible to fully exclude built-up structures or differentiate between types of urban structures. However, this should not justify the inclusion of all built-up areas, it rather points out methodological shortcomings that should be addressed thoroughly.

\subsection{Participatory assessments}

The approaches discussed so far start with biophysical properties of the system. There are also approaches that start with the exchange value, use value or benefits related to ecosystem services examining, for example beneficiaries and their valuation of nature (Spangenberg et al., 2014). In this context, participatory approaches are recommended, for example to incorporate local knowledge and stakeholder preferences in ecosystem service assessments (Brown et al., 2012; Fagerholm et al., 2012). Particularly, cultural ecosystem services move more and more into the focus of research, introducing the notion of stakeholder participation in ecosystem service studies (Beichler, 2015; Kabisch \& Haase, 2014; Kabisch, 2015; Voigt et al., 2014). Assessing the relative importance of ecosystem services in terms of human well-being is of particular interest in urban environments. On the one hand, as ecosystem services become scarce, they are perceived more directly increasing the relative value. On the other hand, substitution possibilities in terms of man-made services (e.g. for recreation) increase in cities, which might reduce the value (Daniel et al., 2012; Gómez-Baggethun \& Barton, 2013). Participatory assessment approaches could start with a categorical choice assessing specific areas (cf. section 4.1), on site surveys (Voigt et al., 2014), or participatory mapping approaches (Beichler 2015). Considering the latter, participants directly identify and delineate areas that provide ecosystem services on a map, whereby valuable data even for large urban regions can be derived, which enables to understand what is perceived as important ecosystem service providing unit (Beichler, 2015; Hagemeier-Klose et al., 2014). In this regard, researchers need to deal with results in which urban built-up areas might be considered as an ecosystem by the participants with a high ecosystem service supply. However, to reliably differentiate between built-up areas and ecosystems detailed ground truthing would be needed. Looking at participatory approaches with reference to section 2 , one might argue that it is challenging to explain to participants as how ecosystems and ecosystem services are defined. By contrast it could also be argued that a specific case study in this regard does not require an explanation of the in-depth scientific knowledge.

\subsection{Assessing multiple ecosystem services of social- ecological systems}

Urban areas comprise closely intertwined systems with dynamic interactions between social, technological and ecological structures and processes (Mörtberg et al., 2012; Reyers et al., 2013). In that context, urban built-up structures could be understood as complex social-ecological systems (Moffatt \& Kohler, 2008). The study of Tiwary and Kumar (2014) highlights that to understand the urban microenvironment, an integrated assessment of green and grey infrastructure is needed. Moreover, scale issues need to be considered for both the social and the ecological subsystem (Moffatt \& Kohler, 2008; Müller et al., 2010b; Scholes et al., 2013). However, current assessment approaches often emphasize ecological factors (Reyers et al., 2013). Moreover, the results are limited in evaluating the provision and use of multiple ecosystem services and trade-offs between them (Bennett et al., 2009; Haase et al., 2014). Although the CORINE dataset is too broad to allow for a differentiation between e.g. different types of settlements, Burkhard et al. (2012b) illustrated that it is possible to set different land use classes in relation through the assessment of all ecosystem services categories including ecosystem integrity. In order to analyse ecosystem service flows, bundles and trade-offs, it could be 
feasible to include all kinds of urban structures. Studies could illustrate that the relative capacity in terms of provisioning ecosystem services of a natural ecosystem (e.g. grassland) and a constructed one (e.g. green bridge) might be the same (e.g. biomass), but the overall services generated could differ. In managed ecosystems, such as agricultural areas, provisioning services are maximized at the cost of other services. Accordingly, as shown for different ecosystem services, an exploitation of ecosystems has both benefits and costs for society (Hermann et al., 2011). In this regard, an analysis of the ecosystem service of all kinds of urban structures taking human input and modification into account could enhance the understanding of ecosystem service bundles and trade-offs.

\section{Key Issues}

- The detailed scientific discourse and decisions on the inclusion or exclusion of urban structures are rarelymade transparent in ecosystem service assessments.

- Should the decision to include solely some urban structures or all of them be based on theoretical considerations or practical/ technical requirements? The ecosystem and ecosystem service definition simultaneously arises from and feeds back to general decisions about scale issues and the interpretative value of results.

\section{Discussion and research challenges}

T his paper illustrates the ongoing scientific discussion on the handling of urban structures in the application of the ecosystem service concept, including the risk that the normative principle of the concept could be missed. Interestingly, during the discussion several controversial issues have been uncovered, which imply several research challenges for the ecosystem service concept in general that are described in the following.
Which urban structures can be differentiated as a starting point for ecosystem service assessments? Urban structures can be named as 'urban ecosystems' according to the meaning the term has in different ecosystem concepts - be it in a strict meaning to a broader understanding referring to processes. Nonetheless, to which structure the term 'ecosystem' can be applied differs between the different ecosystem concepts. Considering the human input and modification, here the four different classes of urban structures natural, managed, constructed and overbuilt, were differentiated relating to different ecosystem definitions (cf. section 2). As summarized by Lamarque et al. (2011), the objectives of ecosystem service approaches range from biodiversity conservation to landscape multifunctionality, which have different implications considering the inclusion of urban structures in ecosystem service assessments. Applying a strict ecosystem definition suggests a focus on natural and managed ecosystems mainly referring to urban blue and green areas. Those approaches give important arguments for nature conservation in urban areas. As shown by Bolund \& Hunhammar (1999) urban blue and green areas contribute to the delivery of multiple ecosystem services including regulating, provisioning and cultural ones. Strategies to protect natural ecosystems are of high importance, as urban areas cannot substitute their functioning (Kowarik, 2011). However, a narrow definition of ecosystem services in urban areas based on natural ecosystems does not correspond to reality in central Europe (Grunewald \& Bastian, 2015). As such, a general exclusion of built-up structures could lead to an underestimation of bundles of ecosystem services influencing the well-being of the urban population. Studies that apply such a simplified approach to urban areas could fail to identify underlying mechanisms and are thus not useful to urban planners and managers (Alberti, 2005).

In urban areas multiple conflicting land use interests are coupled with a lack of space (Bezák \& Lyytimäki, 2011). However, also very dense urbanized areas could have a lot of urban green, e.g. New York and Berlin increase by population, but look for sufficient green provision (Kabisch \& Haase, 2014; Larondelle et al., 2014b). Such a multifunctional approach in 
urban development contributes to maintaining and improving the generation of urban ecosystem services. Hereby the individual contributions of urban ecosystems to ecosystem service provision might be small, but the sum could be of significant value (Bolund \& Hunhammar, 1999). In accordance, due to the supply deficit in cities even very degraded or constructed ecosystem could be of high importance. Studies that include urban built-up structures could identify barriers disrupting the exchange between ecosystems and the associated value of overbuilt or constructed ecosystems. As Moffatt \& Kohler (2008) put it in theory built systems can be designed in a way that they still support environmental services upon which society depends. In line with that, the ecosystem service approach can assist in designing nature-based solutions by showing alternatives to technology based infrastructure, or in case of interventions that involve the manipulation of ecosystems foster solutions that could use nature e.g. green roofs or green walls (Neßhöver et al., 2017). The possibility to point out management options to maintain ecosystem services or the connection of ecosystems despite construction gives an argument to include all classes of urban structures into the assessment of ecosystem service potentials. In any case, the approach should be transparent, but often case studies do not provide sufficient information on how urban structures are defined (Luederitz et al., 2015). Here, the proposed classification natural, managed, constructed and overbuilt ecosystems in relation to differing ecosystem definition might serve as an orientation towards a more transparent reporting, which is generally of importance as the challenge of framing "nature" applies in other contexts as well (e.g. nature-based solutions Neßhöver et al., 2017).

Nonetheless, it is evident that urbanisation and the related overbuilding of natural ecosystems are associated with an extensive loss of ecosystem services (Alberti, 2005; Mooney et al., 2009). This brings us to the question which services provided by urban structures can be understood as ecosystem services? The discussion in section 3 revealed that in principle all classes of urban structures could be included in existing ecosystem service frameworks, as these do not directly refer to a specific ecosystem definition, but rather general to biophysical structures and processes. However, on the one hand, for every case study the ecosystem definition is inherently related to methodological considerations (cf. section 4). On the other hand, ecosystem service assessment are intended to serve as a tool in identifying and framing problems as well as to compare management alternatives, which involve trade-offs between ecosystem services (Granek et al., 2010; Hauck et al., 2013). In this connection, equating ecosystem service values derived in individual case studies on urban ecosystem service assessment e.g. for green roofs and natural forests could be misleading, since overbuilt and constructed ecosystems are degraded and limited in the provision of multiple services. Yet, the same holds true in other environments. Comparing the ecosystem services provided by a forest and a cropping system without consideration of human input and the status of the ecosystem would be misleading (Barot et al., 2017). Thus, it is important to include all ecosystem service groups as well as the ecosystem state within an assessment study, to provide sufficient information for management trade-offs (Müller et al., 2010b). Otherwise, an undifferentiated comparison of results of individual studies (with differing assumptions considering ecosystem definition) could compromise the normative principle of the ecosystem service concept. Until now, the extent to which case studies on ecosystem services can be compared still remains very limited in the urban context (Luederitz et al., 2015) but also in general for anthropized and managed ecosystems (Barot et al., 2017), which hampers a systematic meta-analysis across case studies. Consequently, in order to understand the spatial relations between ecosystem services as well as ecosystem service supply and demand there is a need for approaches that take multiple ecosystem services, the status of the ecosystem and human influence into account ensuring the comparability of case studies.

Looking at the conceptual considerations (section 3 ), it was emphasised that humans are at the same time part of the system (influencing ecosystem service provision via input) and the main actors that change the system properties (human modification) that are relevant for the definition of ecosystems. 
There seems to be a conceptual inconsistency in the ecosystem service framework as human input is considered in the ecosystem service definition, while human modification is considered only indirectly via the structures and processes (i.e. the ecosystem and its state). It remains an open question whether it is feasible to consider biophysical structures and processes separately in the ecosystem service definition. There is a need to clarify the link between the ecosystem and the ecosystem services definition. However, it is argued here that the main challenge does not relate to an adaptation of ecosystem service frameworks, as the essential elements are included. In fact, a lot of ecosystem service studies acknowledge that ecosystem services might be a result of the interaction of ecological processes and human influences (input, accessibility etc.), but a comprehensive consideration in indicator frameworks or an assignment of indicators to the different conceptual elements is still lacking (Albert et al., 2016; Barot et al., 2017; Burkhard et al., 2014; Heink et al., 2016). Consequently, the research challenge rather relates to the operationalization of the ecosystem service concept for assessment. Here, different assessment methods have been reviewed (cf. section 4) in order to answer the question are the theoretical considerations and differentiations viable in ecosystem service assessment. It needs to be acknowledged that with regard to the practical ecosystem service assessment the different types of urban ecosystems are difficult to map, since the transitions between human input and modification are fuzzy and both are interacting. Moreover, the identification of urban structures that provide ecosystem services strongly depends on context and scale (Andersson et al., 2015). As discussed above, in principle, all urban structures might be studied concerning their potential to provide ecosystem services, as an comprehensive analysis of ecosystem state as well as input and modification would enable to differentiate ecosystem services from manmade services. However, taking human effects on ecosystems, their services, and related values into account as well as separating human input and the service provided by the ecosystem itself remains a complex scientific challenge (Barot et al., 2017; Burkhard et al., 2014; Daily et al., 2009; de Groot et al., 2010). Consequently, research regarding gradients and thresholds related to human input, human modification, and ecosystem integrity as well as their interactions is needed.

Regardless of the detailed theoretical debate on the ecosystem service concept, the underlying urban ecosystem definitions and related decisions taken are rarely reflected in case studies on urban ecosystem services. The decision on the inclusion or exclusion of specific urban structures arises from and feeds back to decisions about scale issues and the meaning of results. These are likely to differ with regard to the objective of the respective study (e.g. biodiversity conservation or maintaining ecosystem service flows). In future research, the considerations regarding theoretical basis (underlying normative assumptions and relation to the different conceptual elements), the practical requirements (data and method restrictions) and implications thereof with regard to the meaning of results should to be made transparent in order to reach comparability between urban ecosystem service assessments.

Finally, stakeholders have different requirements in terms of spatial information (Hauck et al., 2013). Thus, research difficulties in terms of scale, data processing and availability etc. (cf. section 4), need to be coupled with the stakeholders' demands for clear, simple and easy-to-use reporting systems (Daily et al., 2009; Potschin, 2009). Furthermore, to assist decision-making, knowledge on ecosystem services should allow for negotiation, target setting and the integration across disciplinary boundaries (Termorshuizen \& Opdam, 2009). As such, the application of the ecosystem service concept could enable an open process including all potentially important urban structures leaving the final decision up to the stakeholders.

\section{Conclusions}

$E$ cosystem services in urban areas are of high relevance for both the well-being of the city's population and the ecological connectivity, thus give important practical implications to supplement 
conservation measures. Nevertheless, it should be unequivocal that, with respect to the normative principle of the ecosystem service concept, smaller units of urban areas, such as green roofs represent no alternative to natural forests. So, does the ecosystem service concept reach its limits in urban environments? The problem of defining an ecosystem becomes particularly apparent in urban environments. Yet, the gradual transition between natural and human influence that determines the ecosystem service potential is a challenge that applies in any environment. We argue that the ecosystem service concept does not reach its limits in urban environments, but urban environments represent an interesting extreme case characterized by multifunctionality and a high degree of human modification. This increases complexity in terms of conceptual and methodological aspects as well as target setting pointing at key issues related to ecosystem services in general. Firstly, from a conceptual point of view, natural, managed, constructed and overbuilt systems can be analyzed using existing ecosystem service frameworks, but when dealing with urban or other modified ecosystems, human input, modification and ecosystem status are essential elements. There is a need to clarify the link between the ecosystem and the ecosystem services definition and a transparent reporting on how "ecosystem", "urban" or "nature" is framed. Secondly, to facilitate comparability between ecosystem service assessments the theoretical basis (normative assumptions and relation to conceptual elements), the practical requirements (data and method restrictions) and implications thereof should to be made transparent. Finally, case studies that include modified ecosystems are needed to enhance the understanding of the underlying mechanisms related to ecosystem service bundles and trade-offs, as the identification of barriers disrupting the exchange between ecosystems can assist planning (e.g. green-infrastructure and naturebased solutions). There is a need for comprehensive approaches that take multiple ecosystem services, the status of the ecosystem, human input and human modification into account to bring forward research on the spatial relations between ecosystem services. Here, the identification of thresholds related to levels of human influence and self-organization of ecosystems is a key challenge future research towards an integrated analysis of ecosystem services in different environments.

\section{References}

Albert, C.; Bonn, A.; Burkhard, B.; Daube, S.; Dietrich, K.; Engels, B.; Frommer, J.; Götzl, M.; GrêtRegamey, A.; Job-Hoben, B.; Koellner, T.; Marzelli, S.; Moning, C.; Müller, F.; Rabe, S.; Ring, I.; Schwaiger, E.; Schweppe-Kraft \&B.; Wüstemann, H. 2016. Towards a national set of ecosystem service indicators: Insights from Germany. Ecologial Indicators 61, 38-48.

Alberti, M. 2005. The Effects of Urban Patterns on Ecosystem Function. International Regional Science Review 28, 168-192.

Andersson, E.; McPhearson, T.; Kremer, P.; GomezBaggethun, E.; Haase, D.;Tuvendal, M. \& Wurster, D. 2015. Scale and context dependence of ecosystem service providing units. Ecosystem Services 12, 157-164.

Barot, S.; Yé, L.; Abbadie, L.; Blouin, M. \& Frascaria, N. 2017. Ecosystem services must tackle anthropized ecosystems and ecological engineering. Ecological Engineering 99, 486-495.

Bastian, O.; Grunewald, K.; Syrbe, R.-U.; Walz, U. \& Wende, W. 2014. Landscape services: the concept and its practical relevance. Landscape Ecology 29, 1463-1479.

Bastian, O.; Haase, D. \& Grunewald, K. 2012. Ecosystem properties, potentials and services The EPPS conceptual framework and an urban application example. Ecologial Indicators 21, 7-16. 
Bastian, O.; Syrbe, R.-U.; Rosenberg, M.; Rahe, D. \& Grunewald, K. 2013. The five pillar EPPS framework for quantifying, mapping and managing ecosystem services. Ecosystem Services $4,15-24$.

Beichler, S.A., 2015. Exploring the link between supply and demand of cultural ecosystem services - towards an integrated vulnerability assessment. International Journal of Biodiversity Science, Ecosystem Services \& Management 11, 250-263.

Bennett, E.M.; Peterson, G.D. \& Gordon; L.J. 2009. Understanding relationships among multiple ecosystem services. Ecology Letters 12, 1394404.

Bezák, P. \& Lyytimäki, J. 2011. Complexity of urban ecosystem services in the context of global change. Ekologia 30, 22-35.

Bolund, P. \& Hunhammar, S., 1999. Ecosystem services in urban areas. Ecological Economics 29, 293-301.

Breuste, J.; Haase, D. \& Elmqvist, T. 2013a. Urban Landscapes and Ecosystem Services. In: Wratten, S.; Sandhu, H.; Cullen, R. \& Costanza, R. (eds.): Ecosystem Services in Agricultural and Urban Landscapes. Wiley.

Breuste, J.; Qureshi, S. \& Li, J. 2013b. Scaling down the ecosystem services at local level for urban parks of three megacities. Hercynia N. F. 46, 1-20.

Brown, G.; Montag, J.M \& Lyon, K. 2012. Public Participation GIS: A Method for Identifying Ecosystem Services. Society \& Natural Resources 25, 633-651.

Burkhard, B.; de Groot, R.; Costanza, R.; Seppelt, R.; Jørgensen, S.E. \& Potschin, M. 2012a. Solutions for sustaining natural capital and ecosystem services. Ecologial Indicators 21, 1-6.
Burkhard, B.; Kandziora, M.; Hou, Y. \& Müller, F. 2014. Ecosystem service potentials, flows and demandsconcepts for spatial localisation, indication and quantification. Landscape Online 34, 1-32.

Burkhard, B.; Kroll, F.; Müller, F. \& Windhorst, W. 2010a. Landscapes' Capacities to provide ecosystem services - a concept for land-cover based assessments. Landscape Online 15, 1-22.

Burkhard, B.; Kroll, F.; Nedkov, S. \& Müller, F. 2012b. Mapping ecosystem service supply, demand and budgets. Ecologial Indicators 21, 17-29.

Burkhard, B.; Petrosillo, I. \& Costanza, R. 2010b. Ecosystem services - Bridging ecology, economy and social sciences. Ecological Complexity 7, 257259.

Costanza, R.; D’Arge, R.; De Groot, R.; Farber, S.; Grasso, M.; Hannon, B.; Limburg, K.; Naeem, S.; O'Neill, R. V; Paruelo, J.; Raskin, R.G.; Sutton, P. \& Van den Belt, M. 1997. The value of the world's ecosystem services and natural capital. Nature 387, 253-260.

Currie, W.S. 2011. Tansley review Units of nature or processes across scales? The ecosystem concept at age 75. New Phytologist 21-34.

Daily, G.C. 1997. Nature's services: societal dependence on natural ecosystems. Island Press, Washington, DC.

Daily, G.C.; Polasky, S.; Goldstein, J. \& Kareiva, P.M. 2009. Ecosystem services in decision making: time to deliver. Frontiers in Ecology and the Environment 7, 21-28. 
Daniel, T.C.; Muhar, A.; Arnberger, A.; Aznar, O.; Boyd, J.W.; Chan, K.M.A.; Costanza, R.; Elmqvist, T.; Flint, C.G.; Gobster, P.H.; Grêt-Regamey, A.; Lave, R.; Muhar, S.; Penker, M.; Ribe, R.G.; Schauppenlehner, T.; Sikor, T.; Soloviy, I. \& Spierenburg, M. 2012. Contributions of cultural services to the ecosystem services agenda. Proceedings of the National Academy of Sciences 109, 8812-8819.

de Groot, R.S.S.; Alkemade, R.; Braat, L.; Hein, L. \& Willemen, L. 2010. Challenges in integrating the concept of ecosystem services and values in landscape planning, management and decision making. Ecological Complexity 7, 260-272.

Ehrlich, P.R. \& Ehrlich, A. 1981. Extinction: The Causes and Consequences of the Disappearance of Species. Random House, New York.

European Commission (EC), 2013. Green Infrastructure (GI) - Enhancing Europe's Natural Capital, COM(2013) 249 final, pp. 1-11,Brussels.

Fagerholm, N.; Käyhkö, N.; Ndumbaro, F. \& Khamis, M. 2012. Community stakeholders' knowledge in landscape assessments - Mapping indicators for landscape services. Ecologial Indicators 18, 421433.

Gómez-Baggethun, E. \& Barton, D.N. 2013. Classifying and valuing ecosystem services for urban planning. Ecological Economics 86, 235245.

Granek, E.F.; Polasky, S.; Kappel, C. V; Reed, D.J.; Stoms, D.M.; Koch, E.W.; Kennedy, C.J.; Cramer, L.; Hacker, S.D.; Barbier, E.B.; Aswani, S.; Ruckelshaus, M.; Perillo, G.M.E.; Silliman, B.R.; Muthiga, N.; Bael, D. \& Wolanski, E. 2010. Ecosystem services as a common language for coastal ecosystembased management. Conservation Biology 24, 207-16.
Grunewald, K. \& Bastian, O. (Eds.) 2015. Ecosystem Services - Concept, Methods and Case Studies. Springer, Heidelberg - London - New York.

Haase, D., 2014. How Is Urban Land Use Unique?, in: Seto, K.C., Reenberg, A. (Eds.), Rethinking Global Land Use in an Urban Era. Cambridge, MA, pp. 299-311.

Haase, D.; Larondelle, N.; Andersson, E.; Artmann, M.; Borgström, S.; Breuste, J.; Gomez-Baggethun, E.; Gren, A.; Hamstead, Z.; Hansen, R.; Kabisch, N.; Kremer, P.; Langemeyer, J.; Rall, E.L.; McPhearson, T.; Pauleit, S.; Qureshi, S.; Schwarz, N.; Voigt, A.; Wurster, D. \& Elmqvist, T. 2014. A quantitative review of urban ecosystem service assessments: concepts, models, and implementation. Ambio 43, 413-33.

Hagemeier-Klose, M.; Beichler, S.A.; Davidse, B.J. \& Deppisch, S. 2014. The Dynamic Knowledge Loop: Inter- and Transdisciplinary Cooperation and Adaptation of Climate Change Knowledge. International Journal of Disaster Risk Science 5, 21-32.

Haines-Young, R. \& Potschin, M. 2010. The links between biodiversity, ecosystem services and human well-being. In: Ecosystem Ecology: A New Synthesis. Raffaelli, D.G. \& Frid, C.L.J. (eds.). BES Ecological Reviews Series, Cambridge University Press, Cambridge.

Hauck, J.; Görg, C.; Varjopuro, R.; Ratamäki, O.; Maes, J.; Wittmer, H. \& Jax, K. 2013. "Maps have an air of authority": Potential benefits and challenges of ecosystem service maps at different levels of decision making. Ecosystem Services 4, 25-32.

Heink, U.; Hauck, J.; Jax, K. \& Sukopp, U. 2016. Requirements for the selection of ecosystem service indicators-The case of MAES indicators. Ecologial Indicators 61, 18-26. 
Hermann, A.; Schleifer, S. \& Wrbka, T. 2011. The concept of ecosystem services regarding landscape research: A review. Living Reviews in Landscape Research 1, 1-37.

Hobbs, R.J.; Arico, S.; Aronson, J.; Baron, J.S.; Bridgewater, P.; Cramer, V.; Epstein, P.R.; Ewel, J.J.; Klink, C.; Lugo, A.E.; Norton, D.; Ojima, D.; Richardson, D.M.; Sanderson, E.W.; Valladares, F.; Vila, M.; Zamora, R. \& Zobel, M. 2006. Novel ecosystems: theoretical and management aspects of the new ecological world order. Global Ecology and Biogeography 15, 1-7.

Jansson, Å. 2013. Reaching for a sustainable, resilient urban future using the lens of ecosystem services. Ecological Economics 86, 285-291.

Kabisch, N. 2015. Ecosystem service implementation and governance challenges in urban green space planning - The case of Berlin, Germany. Land Use Policy 42, 557-567.

Kabisch, N. \& Haase, D. 2013. Green spaces of European cities revisited for 1990 - 2006. Landscape Urban Planning 110, 113-122.

Kabisch, N. \& Haase, D. 2014. Green justice or just green? Provision of urban green spaces in Berlin, Germany. Landscape Urban Planing 122, 129139.

Kandziora, M.; Burkhard, B. \& Müller, F. 2013. Interactions of ecosystem properties, ecosystem integrity and ecosystem service indicators-A theoretical matrix exercise. Ecologial Indicators 28, 54-78.

Knapp, S. 2014. The Urban Garden: A Centre of Interactions between People and Biodiversity. In: Kabisch, N.; Larondelle, N.; Reeve, A. \& Artmann, M. (Ed.), Human-Environmental Interactions in Cities: Challenges and Opportunities of Urban Land Use Planning and Green Infrastructure. Cambridge Scholars Publishing, Newcastle Upon Tyne.
Kowarik, I. 1992. Das Besondere der städtischen Flora und Vegetation 1. Deutscher Rat für Landespflege 61, 33-47.

Kowarik, I. 2011. Novel urban ecosystems, biodiversity, and conservation. Environmental Pollution 159, 1974-83.

Lamarque, P.; Quétier, F. \& Lavorel, S. 2011. The diversity of the ecosystem services concept and its implications for their assessment and management. Comptes Rendus Biologies 334, 441-9.

Larondelle, N.; Haase, D. \& Kabisch, N., $2014 a$. Mapping the diversity of regulating ecosystem services in European cities. Global Environmental Change 26, 119-129.

Larondelle, N.; Hamstead, Z.A.; Kremer, P.; Haase, D. \& McPhearson, T. 2014b. Applying a novel urban structure classification to compare the relationships of urban structure and surface temperature in Berlin and New York City. Applied Geography 53, 427-437.

Luederitz, C.; Brink, E.; Gralla, F.; Hermelingmeier, V.; Meyer, M.; Niven, L.; Panzer, L.; Partelow, S.; Rau, A.-L.; Sasaki, R.; Abson, D. J.; Lang, D.J.; Wamsler, C. \&von Wehrden, H. 2015. A review of urban ecosystem services: Six key challenges for future research. Ecosystem Services 14, 98-112.

Martínez-Harms, M.J. \& Balvanera, P. 2012. Methods for mapping ecosystem service supply: A review. International Journal of Disaster Risk Science 8, 17-25.

MEA, 2005. Ecosystems and Human Well-being: Millennium Ecosystem Assessment. Island Press, Washington, DC.

Milcu, A.I.; Hanspach, J.; Abson, D. \& Fischer, J. 2013. Cultural ecosystem services: A literature review and prospects for future research. Ecology and Society 18(3), art44 
Moffatt, S. \& Kohler, N. 2008. Conceptualizing the built environment as a social- ecological system. Build. Res. Inf. 36, 248-268.

Mooney, H.; Larigauderie, A.; Cesario, M.; Elmquist, T.; Hoegh-Guldberg, O.; Lavorel, S.; Mace, G.M.; Palmer, M.; Scholes, R. \& Yahara, T. 2009. Biodiversity, climate change, and ecosystem services. Current Opinion in Environmental Sustainability $1,46-54$.

Mörtberg, U.; Haas, J.; Zetterberg, A.; Franklin, J.P.; Jonsson, D. \& Deal, B. 2012. Urban ecosystems and sustainable urban development-analysing and assessing interacting systems in the Stockholm region. Urban Ecosystems 16, 763-782.

Müller, F. \& Burkhard, B., 2012. The indicator side of ecosystem services. Ecosystem Services 1, 26-30.

Müller, F.; Burkhard, B. \& Kroll, F. 2010a. Resilience, Integrity and Ecosystem Dynamics: Bridging Ecosystem Theory and Management. In: Otto, J.-C. \& Dikau, R. (eds.). Landform - Structure, Evolution, Process Control, Lecture Notes in Earth Sciences 115. Springer-Verlag, Heidelberg Berlin, pp. 221-242.

Müller, F.; de Groot, R. \& Willemen, L. 2010b. Ecosystem services at the landscape scale: The need for integrative approaches. Landscape Online 23, 1-11.

Naveh, Z. 2000. The total human ecosystem: Integrating ecology and economics. Bioscience 50, 357-361

Naveh, Z. \& Lieberman, A.S. 1994. Landscape Ecology: Theory and Application, 2nd ed. Springer-Verlag, New York.

Neßhöver, C.; Assmuth, T.; Irvine, K. N.; Rusch, G. M.; Waylen, K. A.; Delbaere, B.; Haase, D.; Jones-Walters, L.; Keune, H.; Kovacs, E.; Krauze, K.; Külvik, M.; Rey, F.; van Dijk, J.; Vistad, O.I.; Wilkinson, M.E. \& Wittmer, H. 2017. The science, policy and practice of nature-based solutions: An interdisciplinary perspective. Science of the Total Environment 579, 1215-1227.

Oberndorfer, E.; Lundholm, J.; Bass, B.; Coffman, R.R.; Doshi, H.; Dunnett, N.; Gaffin, S.; Köhler, M.; Liu, K.K.Y. \& Rowe, B. 2007. Green Roofs as Urban Ecosystems: Ecological Structures, Functions, and Services. Bioscience 57, 823-833.

Odum, E.P.; Odum, H.T. \& Andrews, J. 1971. Fundamentals of ecology. Saunders, Philadelphia.

Pauleit, S. \& Duhme, F. 2000. Assessing the environmental performance of land cover types for urban planning. Landscape Urban Planning 52, 1-20.

Pickett, S.T.A. \& Cadenasso, M.L. 2002. The ecosystem as a multidimensional concept: Meaning, model, and metaphor. Ecosystems 5, 1-10.

Potschin, M. 2009. Land use and the state of the natural environment. Land use policy 170-177.

Reyers, B.; Biggs, R.; Cumming, G.S.; Elmqvist, T.; Hejnowicz, A.P. \& Polasky, S. 2013. Getting the measure of ecosystem services: a socialecological approach. Frontiers in Ecology and the Environment 11, 268-273.

Scholes, R.; Reyers, B.; Biggs, R.; Spierenburg, M.; Duriappah, A. 2013. Multi-scale and cross-scale assessments of social-ecological systems and their ecosystem services. Current Opinion in Environmental Sustainability 5, 16-25.

Schröter, M.; van der Zanden, E.H.; van Oudenhoven, A.P.E.; Remme, R.P.; Serna-Chavez, H.M.; de Groot, R.S. \& Opdam, P. 2014. Ecosystem services as a contested concept: a synthesis of critique and counter-arguments. Conservation Letters 7, 514-523. 
Schwarz, N.; Bauer, A. \& Haase, D. 2011. Assessing climate impacts of planning policies-An estimation for the urban region of Leipzig (Germany). Environmental Impact Assessment Review 31, 97-111.

Seppelt, R.; Fath, B.;Burkhard, B.; Fisher, J.L.; GrêtRegamey, A.; Lautenbach, S.; Pert, P.; Hotes, S.; Spangenberg, J.; Verburg, P.H. \& Van Oudenhoven, A.P.E. 2012. Form follows function? Proposing a blueprint for ecosystem service assessments based on reviews and case studies. Ecologial Indicators 21, 145-154.

Spangenberg, J.H.; von Haaren, C. \& Settele, J. 2014. The ecosystem service cascade: Further developing the metaphor. Integrating societal processes to accommodate social processes and planning, and the case of bioenergy. Ecological Economics 104, 22-32.

Sukopp, H. 1969. Menschlicher Einfluß auf die Vegetation. Vegetatio 17, 360-371.

Termorshuizen, J.W. \& Opdam, P. 2009. Landscape services as a bridge between landscape ecology and sustainable development. Landscape Ecology 24, 1037-1052.

Tiwary, A. \& Kumar, P. 2014. Impact evaluation of green-grey infrastructure interaction on builtspace integrity: an emerging perspective to urban ecosystem service. Science of the Total Environment 487, 350-60.

Transley, A.G. 1935. The use and abuse of vegetational concepts and terms. Ecology 16, 284-307.

Vallés-Planells, M.; Galiana, F. \& van Eetvelde, V. 2014. A classification of landscape services to support local landscape planning. Ecology and Society 19(1), art44.
Voigt, A.; Kabisch, N.; Wurster, D.; Haase, D. \& Breuste, J. 2014. Structural diversity: A multi-Dimensional approach to assess recreational services in urban parks. Ambio 43, 480-491.

Wang, Y.; Bakker, F.; De Groot, R. \& Wörtche, H. 2014. Effect of ecosystem services provided by urban green infrastructure on indoor environment: $A$ literature review. Building and Environment 77, 88-100. 